\section{Aberrant Biomarkers, Leg Anatomy and Pain Parameters are the Risk Factors in Lumbar-Herniated Disc: a Novel Diagnostic Protocol}

Keywords: Protocol for LHD; Low cost diagnostic protocol; Lumbar slipped disc; Herniated disc; Biomarkers for LHD

\begin{abstract}
Objective: To investigate the role of aberrant biochemical markers and leg-musculo- postural features as risk factors in Lumbar-Herniated Disc (LHD) for novel diagnostic protocol.

Methods: Baseline data from 117 patients, average aged $59.84 \pm 7.17$ years, suffering with LHDs for $5.88 \pm 1.92$ years and 117 participants, average aged 58.86 \pm 7.62 years, without LHDs were collected in this cross-sectional study. Separate analyses were performed for participants with and without LHD symptoms confirming with X-ray or MRI. Blood IL-10, TNF-a, CK-MM, and AldoA levels were estimated. Anatomical measurements included bilateral gap at the knees between the short head of the biceps femoris and the level of the bed while supine, diameter of muscles at the thighs, the calves, 4 $\mathrm{cm}$ above and below the patella, straight legs rising, flexions supine and extensions supine and Body Mass Index of both groups using appropriate instruments. The study was also correlated with functiona disability parameters and radiological images.
\end{abstract}

Results: In patients with LHDs who exhibited intervertebral disc degeneration at the lumbar spine having above-mentioned anomalous levels of biomarkers were recorded as their mean $\pm S D$ values $7.84 \pm 1.40 \mathrm{pg} / \mathrm{ml}, 27.04 \pm 5.16 \mathrm{pg} / \mathrm{ml}, 189.05 \pm 58.90 \mathrm{U} / \mathrm{L}$, and $8.08 \pm 1.94 \mathrm{U} / \mathrm{L}$ respectively, the bilateral measurements of leg anatomy and percentage of retrogression of international-approved functional disability outcomes of cohorts with LHD were all were highly significan differences $(p<0.0001)$ when compared to the non-LHD cohorts

Conclusion: It is firmly concluded that the effective diagnostic tool for LHD may be monitored with the help of above-mentioned abnorma biomarker levels and deranged lower extremities along with functional disability parameters confirming with spine radiographic images.

\section{Introduction}

The Lumbar Herniated Disc (LHD) is painful chronic disorder and the clinical symptoms emphasized intervertebral disc degeneration in lumbar region, which occurred due to the rupture of the fibrous ring and protrusion of the nucleus pulposus, resulting which the nerve roots and cauda equina are impinged and stimulated [1-8]. It occurs at any age, but most common for men between the ages 20 to 50 years [9]. It is also found during aging when the vertebral discs lose some of the fluid that helps them maintain flexibility. LHD is a condition, in which jelly-like substance called the nucleus pulposus, slips out through a crack in the tough outer wall, the annulus fibrosus, and put pressure on the nerves and irritates nerves by the chemical so released from the soft jelly causes pain, numbness, weakness in the leg and leads to disability in life $[5,6,8]$.

The common symptoms of LHD are numbness and tingling, weakness in the muscles and pain in the spine radiating to the arms and legs. When the pain causes in the regions of buttocks, thighs, calves, and feet due to the LHD, it is referred to as sciatica or Lumbar

\section{Journal of Orthopedics \& Rheumatology}

\author{
Apurba Ganguly* and Devika Ganguly \\ Department of Research and Development, OPTM Research \\ Institute, India \\ *Address for Correspondence \\ Apurba Ganguly, Founder and Chief Scientist, OPTM Research Institute, \\ Kolkata, India, Tel: +919830389616; E-mail: apurbaganguly15@gmail.com \\ Submission: 29 September, 2018 \\ Accepted: 30 October, 2018 \\ Published: 11 November, 2018 \\ Copyright: () 2018 Ganguly A, et al. This is an open access article \\ distributed under the Creative Commons Attribution License, which \\ permits unrestricted use, distribution, and reproduction in any medium, \\ provided the original work is properly cited.
}

radiculopathy because the pain travels along the path of the sciatic nerve which is the longest nerve in the body that runs from the back of the pelvis, through buttocks, down both legs to the feet. In acute case, LHD can cause permanent weakness around the inner thighs, the backs of the legs, and rectum, paralysis, loss of bowel and bladder control and sexual dysfunction [10].

The researchers have investigated the various risk factors during the progression of LHD, which caused one or more risk factors such as inherited a predisposition; overweight; occupational hazards such as involvement of repetitive lifting, pushing, pulling, bending or twisting; unsafe lifting technique of heavy items like apply force from the legs not the back; sedentary lifestyle with wrong posture; smoking and drinking habits that may lead to reduce the oxygen supply to the discs that grinding-down of the tissues; heavy exercises; long continuous driving or riding on bumpy roads in a vehicle damages both the discs and spinal structure [11-17].

The pathogenicity of LHD derives from mechanical compression, chemical radiculoneuritis and autoimmunity. According to the researchers, all these factors are proved to be the effect of anatomical factors combined with external physical factors $[3,6]$. The primary diagnosis of LHD by physical examination with the observation of symptoms such as reflexes, identification of tender regions in the back, muscle strength, range of motion, walking ability, and sensitivity to touch. After the physical examination to confirm the LHD various diagnostic methods such as X-ray to ruled out the compression between the vertebrae, formation of osteophytes, etc. The Magnetic Resonance Imaging (MRI) or Computer Tomography (CT) images that can identify the location of the disk degeneration along with the affected nerves. Another tool is a Discogram, which identify the fracture in each disc, and finally Myelogram to detect the herniated disc exerting any pressure on the spinal cord and nerves are well-established [8,11-17]. The MRI and/or CT scans have some limitations because patients are having with pacemaker, metal prostheses, etc. unable to diagnose with these techniques. It is also noteworthy that MRI can only detect LDH but not nerve root compressions [18]. 
However, deranged anatomical features can be detected during LHD. According to Debrunner and Vucetic and Svensson, lumbar sagittal Range of Motion (ROM) is an important parameter, which can be measured by using a Kyphometer [19,20]. According to him, first test was passive flexion of the hip with the knee extended and second test was passive hip flexion with the knee flexed. Tendon reflexes can suitable parameter in the patient supine and the hips and knees flexed. The power of the foot extensors was tested without resistance, with the patient in a supine position with hips and knees flexed. Besides these Ganguly has developed several anatomical parameters and emphasized that degenerative changes in lumbar region always lead to bilateral degenerative changes in knee-joints and vice-versa [21]. According to him, sensation of pain cannot only be the parameter of degeneration.

Moreover, biochemical markers viz. IL-10, TNF- $\alpha$, CK-MM and AldoA are the risk factors for LHD. The elevated level of TNF- $\alpha$ have been considered as a pro-inflammatory marker to identify quantum of inflammation around the vertebral regions while the level of serum IL-10 is an anti-inflammatory marker to detect inflammation during the prevention of disks or muscles damage [22-26]. The level of serum $\mathrm{CK}-\mathrm{MM}$ is a biochemical marker to detect connective tissue damage and elevated level of serum AldoA have been considered a biomarker to identify the skeletal muscle damage and inflammatory muscle diseases [27-28].

It has already been investigated that the muscle impairment causes pain, inflammation and functional disabilities in the patients of LHD [29]. But the combination of analysis of biochemical markers, anatomical measurements and different indices for identifying pain and physical functional disabilities to diagnosis LHD are lacking, while all the tests can be done easily with minimum cost. A combined approach using all these parameters to detect risk factors for LHD is an endeavor in its first time.

The objective of present study is to develop the low-cost and combined diagnostic tool for LHD by analyzing the aberrant biochemical parameters such as IL-10, TNF- $\alpha$, CK-MM and AldoA, deranged anatomical features, Anomalies in international acclaimed functional disabilities and overweight like VAS, KPS, LEFS, ODI and BMI together with radiological images as assessed by KL grading scale in the patients whether there is no pain syndrome or discomfort or deformities observed in the vertebral region and/or lower extremities much before identifying with the help of most costly and sophisticated method like radiographic images. Therefore, the present study has portent the novelty concepts for diagnosis of LHD into the relevant biomedical and neuro-muscular-anatomical categories.

\section{Materials and Methods}

\section{Recruitment of participants}

A total of 432 participants ( $59.57 \%$ men), aged 35 to 65 years old who were treated including the cohorts who came along with the patients as patient party at OPTM Health Care (P) Ltd. centers in Kolkata, Delhi and Mumbai, India from July 2016 to February 2017 were evaluated in this study. The study protocol was evaluated and approved by the OPTM Research Institute Ethics Committee. The institute is registered with the government. An Institutional Review Board-approved consent form for the physical examinations, blood sample collections and radiological images (X-rays or CT scan or MRI) required for the study was signed by all cohorts in the first phase of the screening procedure.

\section{Exclusion criteria}

a) One hundred and five patients (28 females and 77 males) out of 432 patients were excluded for having another pathological condition that could explain the existing symptoms, such as rheumatic diseases, Osteochondritis diseases, Inter-articular fractures, Congenital dysplasia, radicular syndrome, joint symptoms caused by malignant tumors, Baker's cyst, Perthes disease, Plico syndrome, Dermatomyositis and polymyositis diseases, Iiopectineal or trochanteric bursitis, Bone and joint infectious diseases and ischemic bone necrosis.

b) The following additional exclusion criteria of 93 patients (71 females and 22 males) out of balanced 327 patients were considered: patients with multiple drug dependence; a history of cancer, including carcinomatosis and granulocytic leukemia; patients with cuts, wounds, or any type of chronic skin disease; a history of severe neurological diseases; a history of chronic liver, kidney and heart diseases; and patients who did not agree to a physical evaluation and/ or attend weekly follow-up visits.

\section{Study design}

After evaluating the exclusion criteria, 117 (36 females and 81 males) of remaining 234 subjects who had no complain of pain, or visual inflammation or discomfort in quality of life and no abnormalities observed in muscles, joint and lower limb functions and no signs of LHD as evidenced by the analyses of serum IL-10, TNF- $\alpha$, CK-MM and AldoA, electromyography, and radiological images (X-ray or CT-scan or MRI) were considered as healthy control subjects and termed as 'subjects without LHD'. The remaining 117 (36 females and 81 males) subjects with significant pain syndromes, discomfort, imbalanced quality of life, impaired joint and lower limb functions due to muscle wasting, weakness and degeneration in the lumbar region, as evidenced by analysis of retrograded levels of serum IL-10, TNF- $\alpha$, CK-MM and AldoA, and radiological images (CT-scan or X-ray or MRI) were considered as experimental subjects and termed as 'subjects with LHD'. The baseline demographic characteristics of all patients are presented in Table 1. Co-morbidities were also assessed using the Charlson co-morbidity index and methods described by Katz et al. and Singh et al. [30,31].

\section{Evaluation of specific biochemical parameters in blood}

A 4-ml of blood was collected in tubes coated with heparin (25 $\mathrm{IU} / \mathrm{ml}$ ) by venom puncture from each subject with and without LHD of experimental and control groups. Blood samples were then centrifuged at $1000 \times \mathrm{g}$ for $10 \mathrm{~min}$ at $4{ }^{\circ} \mathrm{C}$ to obtain serum. According to Vilcek and Lee and Gesser et al. the biochemical parameters as TNF- $\alpha$ and IL-10 in blood of patients were measured by ELISA (enzyme-linked immunosorbent assay) method using the kits from R\&D System [32,33], Germany (Cat. \# DY210 and DY217B). All other chemicals were used in analytical grade supplied by Sigma (St. Lousis, MO, USA). The antibody of TNF- $\alpha$ and IL-10 were collected from Santa Cruze, Biotechnology, Inc (CA, USA).

A 5-ml blood sample was collected in a plain vial from each 
subject of both the groups. Blood samples were then centrifuged at $1000 \times \mathrm{g}$ for $10 \mathrm{~min}$ at $4{ }^{\circ} \mathrm{C}$ to obtain serum. Finally, the serum was used to analyse CK-MM and AldoA levels for each subject of both the groups with or without LHD. The biomarkers were rigorously analysed. CK-MM (U/L) levels were quantitatively assessed using a Creatine Kinase-MM kit (CK-MM/CPK-MM/CK-3) and an immunoassay (Aalto Scientific, Limited, USA). The kit was developed based on the methods reported by Cabaniss [34]. AldoA levels (U/L) were quantified using an ALDOLASE (ALS) RX MONZA AD 189 kit (Randox Laboratories Ltd, Antrim, UK) based on a photometric assay at a wavelength of $340 \mathrm{~nm}$. The kit was developed according to the method reported by Feissli [35]. The subjects suffering from LHD with inflammation, muscle weakness, and disc degeneration were studied to identify a specific biochemical parameter, such as IL10, TNF- $\alpha$, CK-MM, and AldoA levels, in the affected population Each test for each participant of experimental and control group has been rechecked by the BS-240 Mindray fully automated biochemistry analyser before reporting the final test results.

All blood tests were conducted under the supervision of the Chief biochemist in the Galaxy Medical Centre, an ISO 9001: 2015 certified lab with Registration No. L/004-(05)-15/0129 under the W.B Clinical Establishment Act, 1950.

The mean, standard deviation (SD) and their mean differences (MDs), 95\% confidence intervals (CIs), and p-values of the biomarkers such as IL-10, TNF- $\alpha$, CK-MM and AldoA respectively were evaluated for each cohort of both the groups. Their percentages of retrograded levels of experimental subjects compared to the healthy control subjects were graphically evaluated.

The ratio of two biomarkers such as IL-10 and TNF- $\alpha$, and CK$\mathrm{MM}$ and AldoA for both the groups were separately evaluated and their mean standard deviation, mean difference and 95\% CI were also evaluated.

\section{Evaluation of Pearson's correlation coefficients between two biomarkers}

To determine the predictive values of the two biomarkers in patients with LHD, the Pearson's correlation coefficients between two biochemical markers such as IL-10 for experimental cohorts with LHD (IL-10 ${ }^{\text {Exp }}$ ) and Il-10 for non-LHD healthy control cohorts (Il-10 ${ }^{\text {Con }}$ ), TNF- $\alpha$ for experimental cohorts with LHD (TNF- $\left.\alpha^{\text {Exp }}\right)$ and TNF- $\alpha$ for non-LHD healthy control cohorts (TNF- $\left.\alpha^{\mathrm{Con}}\right)$, (CK-MM for experimental cohorts with LHD (CK-MM ${ }^{\mathrm{Exp}}$ )and CK-MM for nonLHD control cohorts (CK-MM $\left.{ }^{\mathrm{Con}}\right)$, Aldo A for experimental cohorts with LHD (AldoA Exp) and AldoA for non-LHD control cohorts (AldoA Con), the ratio of IL-10 and TNF- $\alpha$ Al for experimental

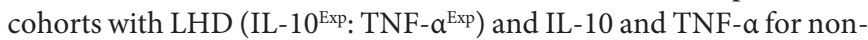
LHD control cohorts (IL-10 ${ }^{\text {Exp }}$ TNF- $\alpha^{\text {Exp }}$ ), CK-MM and AldoA for experimental cohorts with MD-OAD (CK-MM ${ }^{\text {Exp:Aldo }}{ }^{\text {Exp }}$ ) and CK$\mathrm{MM}$ and AldoA for non-MD-OAD control cohorts (CK-MM ${ }^{\mathrm{Con}}$ :Aldo $\mathrm{A}^{\mathrm{Con}}$ ) along with their respective p-values were separately evaluated.

\section{Evaluation of anatomical parameters}

Physical examinations were evaluated for each subject of both the groups including anatomical measurements such as bilateral gap at the knees between the point of short head of the biceps femoris at the lateral knee and the surface of the bed while supine (KGB), bilateral diameter of muscles at the thighs (DTM), the calves (DCM), bilateral diameter of muscles connected with the knee joints $4 \mathrm{~cm}$ above the patella (DAP) and $4 \mathrm{~cm}$ below the patella (DBP), bilateral straight legs raising in supine (SLRS), in prone (SLRP) and in sitting (SLRSit), bilateral angles of flexion in supine (KFS), in prone (KFP), in standing (KFSt) and bilateral angles of extension in supine position (KES), in prone(KEP) and in standing (KESt).

A meter scale was used to measure KGB. The parameters viz. DTM, DCM, DAP and DBP measurements were performed using a meter tape and a goniometer was used for straight leg raising, flexion and extension measurements in accordance with the American Academy of Orthopedic Surgeons (AAOS) [36].

The mean, Standard Deviation (SD) and their Mean Differences (MDs), 95\% Confidence Intervals (CIs), and p-values of the abovementioned anatomical parameters were evaluated for both the groups separately

\section{Evaluation of pain under Visual Analogue Scale (VAS)}

Visual Analogue Scale (VAS) for pain is a unidimensional measure of pain intensity [37]. Observation of patient's perceived symptoms of pain intensity in the last 24 hours was point out on the line of $100 \mathrm{~mm}$. The pain intensity marked as no pain $(0-4 \mathrm{~mm})$, mild pain $(5-44 \mathrm{~mm})$, moderate pain $(45-74 \mathrm{~mm})$ and severe pain (75-100 mm) separately for right leg, left leg and lower back pain under the scale was evaluated for each patient of both the groups. The percentage of enhancement of pain in the right and left legs and lower back was evaluated for all the patents of experimental group separately compared to the subjects of control group. Their mean, $\mathrm{SD}$ and $\mathrm{p}$-values for overall and separately by gender were also graphically evaluated.

\section{Evaluation of Karnofsky Performance Status (KPS) score}

Karnofsky Performance Status (KPS) score is used to determine a patient's prognosis to carry out daily activities. This is used to compare effectiveness of different therapies and to assess the prognosis in individual patient. A higher score indicates the patient is better able to carry out daily activities and it ranges from 0 to 100 [38]. The percentage rating criteria of the scale has been broadly classified as under: Normal no complaints; no evidence of disease (100\%); Able to carry on normal activity; minor signs or symptoms of disease (90\%); Normal activity with effort; some signs or symptoms of disease (80\%); Cares for self; unable to carry on normal activity or to do active work (70\%); Requires occasional assistance, but is able to care for most of his personal needs (60\%); Requires considerable assistance and frequent medical care (50\%); Disabled; requires special care and assistance (40\%); Severely disabled; hospital admission is indicated although death not imminent (30\%); Very sick; hospital admission necessary; active supportive treatment necessary (20\%); Moribund; fatal processes progressing rapidly (10\%); Dead (0\%). The KPS is evaluated for each patient for both the groups. The percentage of increased level was evaluated for all the patents with LHD separately compared with the subjects of control group. Their mean, SD and p-values for both groups for overall and separately by gender were graphically evaluated. 


\section{Evaluation of the Lower Extremity Functional Scale (LEFS)}

According to Binkley et al. the Lower Extremity Functional Scale (LEFS) is a 20 -item questionnaire pertaining to the patient's ability to perform everyday activities [39]. Each of 20 items in the scale are awarded several points varying 0 to 4 , depending on the degree of the impairment when performing the specific activity such as: Extreme difficulty or unable to perform activity (0); Quite a bit of difficulty (1); Moderate difficulty (2); A little bit of difficulty (3); and No difficulty (4). The LEFS is evaluated for each participant of both the groups. The percentage of deteriorated level was evaluated for all the patents separately of experimental group compared with subjects of control group. Their mean, SD and p-values for both groups for overall and separately by gender were graphically evaluated.

\section{Evaluation of Oswestry Disability Index (ODI)}

The Oswestry Disability Index (ODI) or the Oswestry Low Back Pain Disability Questionnaire is an important test of low back functional outcome tool to evaluate a patient's permanent functional disability [40]. In this questionnaire, there are six questions in each ten sections such as Pain intensity; Personal care (washing, dressing etc); Lifting; Walking; Sitting; Standing; Sleeping; Sex life (if applicable); Social life; and Travelling to identify the back or leg pain affecting patient's ability to manage in everyday life. The interpretation of scores have been divided into five categories such as minimal disability $(0 \%$ to $20 \%$ ); moderate disability ( $21 \%$ to $40 \%$ ); severe disability ( $41 \%$ to $60 \%$ ); crippled (61\% to $80 \%)$ and patients are either bedridden or exaggerating their symptoms ( $81 \%$ to $100 \%)$. The ODI is evaluated for each subject of both the groups separately. The percentage of enhancement of low back pain disability was evaluated for all the patents of experimental group separately compared with each subject of control group. Their mean, SD and p-values for both the groups for overall and separately by gender were graphically evaluated.

\section{Evaluation of Body Mass Index (BMI)}

Body weight (in kilograms) was measured without shoes or heavy clothing using an electronic scale. Height (in meters) was measured without shoes using a wall-mounted stadiometer [41]. Body Mass Index (BMI) was calculated for all the patients based on measured weights and heights at the baseline and at the post treatment as weight/ hight2. The percentage of enhancement of body weight was evaluated for all the patients with LHDs separately compared to the non-LHD patents their mean, SD and p-values for both the groups for overall and separately by gender were also graphically evaluated.

Evaluation of Lumbar spine radiographic assessment under KL grading scale

Lateral radiographs of the lumbar spine were obtained with 117 subjects lying on their side with knees bent, Radiographs were scored for lumbar degenerative disc using Kellgren-Lawrance (KL) grade developed by Kellgren and Lawrence as follows: Grade 0, normal; Grade 1,slight anterior wear and osteophytes formation; Grade 2, definite anterior wear and osteophytes formation; Grade 3, osteophytes formation and narrowing of disc; Grade 4, large osteophytes [42], marked disc narrowing, sclerosis of vertebral plates and posterior subluxation. The present study defined a lumbar spine with disc space narrowing with osteophytes or without osteophytes or with bone sclerosis, disc spec narrowing and large osteophytes. KL grades were evaluated at the intervertebral levels from L1-L2 to L5-S1 for all the cohorts for both the groups.

\section{External study reviewers}

All the results and data of cohorts with and without LHD were evaluated by an external reviewing panel, not in contract with the registry cohorts

\section{Data collection and Statistical analysis}

Data were summarized using descriptive statistics for continuous variables (e.g., mean, standard deviation, number of patients, minimum, maximum), frequency tables, or ratios for discrete variables, and 95\% confidence intervals. Statistical analyses were done by using software (Graph Pad Prism, Version,5.0) with repeated measures for student-t test to determine significant values at $\mathrm{p}<0.05$ level along with $\mathrm{r}$ (Pearson's correlation coefficient) values to determine strong and weak correlation among two variables for measuring different improvement parameters of combined-sex, female and male patients separately. The comparison was done between the experimental group and control group. An alpha level of $5 \%$ was established i.e., a p-value less than 0.05 was considered statistically significant.

\section{Results}

\section{Enrolment and baseline characteristics of patients}

A total of 117 patients aged $59.84 \pm 7.17$ years $(69.23 \%$ men) those who were suffering with LHDs for $5.88 \pm 1.92$ years and 117 cohort's $58.86 \pm 7.62$ years without LHD symptom confirmed by X-ray or CTscan or MRI included in the study. All the patients with LHDs were having inflammation, pain, weakness in the muscle specially in the buttock, thigh and calf regions confirmed by the serum tests of IL-10, TNF- $\alpha$, CK-MM and AldoA, and physical functional disabilities as well as increased body weight confirmed by VAS, KPS LEFS, ODI and BMI, and deranged anatomical parameters but the cohorts without LHDs do not notice any significant abnormalities so far as the inflammation, pain, weakness in the muscles, physical functional disabilities, body weight while scanning the documents with the above-mentioned measuring parameters. Baseline demographic characteristics of all patients for both experimental (with LHD) and control (without LHD) groups who were not being treated by oral medications; injections; massage with any type of herbal gels; and any type of alternative interventions or treatments for diminishing pain or inflammation, for muscle relaxation, or to improve of the skeletal muscles one day prior to inclusion in the study and had not undergone discectomy or other kind of surgical intervention to release the compression between the vertebrae within four months prior to the blood tests such as Il-10, TNF- $\alpha$, CK-MM and AldoA were evaluated and shown in Table 1.

The biochemical parameters such as IL-10, TNF- $\alpha$, CK-MM and Aldo A were measured and rechecked by the S-240 Mindray fully automated biochemistry analyser before reporting the final test results for both experimental and control cohorts.

\section{Biochemical parameters}

Table 2 shows that the mean \pm SD levels of IL-10 and TNF- $\alpha$ for 
Citation: Ganguly A, Ganguly D. Aberrant Biomarkers, Leg Anatomy and Pain Parameters are the Risk Factors in Lumbar-Herniated Disc: a Novel Diagnostic Protocol. J Orthopedics Rheumatol. 2018; 5(2): 1

ISSN: 2334-2846

117 combined-sex patients with LHDs were recorded their normal limits (IL-10 $>12 \mathrm{pg} / \mathrm{ml}$ and TNF- $\alpha<15 \mathrm{pg} / \mathrm{ml}$ ) and their differences were highly significant $(p<0.0001)$ when compared to the 117 subjects without LHD. Moreover, the Table 3 shows that the ratios of Il-10

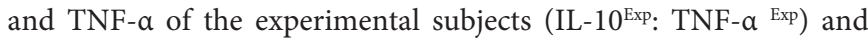

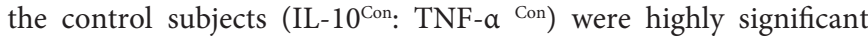
$(\mathrm{p}<0.0001)$ when compared to the subjects without LHD for both overall and separately by gender.

Table 4 shows that the mean \pm SD levels of CK-MM and AldoA for combined-sex, male-only and female-only patients with LHDs were reduced their normal limits (CK-MM: for male $<171$ and female $<145 \mathrm{U} / \mathrm{L}$ and AldoA: $<7.6 \mathrm{U} / \mathrm{L}$ and their differences were highly significant $(\mathrm{p}<0.0001)$ when compared to the subjects without LHD. Moreover, the Table 5 shows that the ratios of CK-MM and AldoA of subjects with LHD (CK-MM ${ }^{\text {Exp }}$ : Aldo $\left.{ }^{\text {Exp }}\right)$ and subjects without LHD $\left(\mathrm{CK}-\mathrm{MM}^{\mathrm{Con}}\right.$ : Aldo $\left.\mathrm{A}^{\mathrm{Con}}\right)$ were also highly significant $(\mathrm{p}<0.0001)$ when compared to the control subjects for both overall and separately by gender.

Table 6 shows none of the correlation coefficients between IL-10 and TNF- $\alpha$ were not significant for both overall and separately by gender.

Table 7 shows the levels of Pearson's correlation coefficients: between CK-MM and AldoA of experimental subjects (CK-MM ${ }^{\mathrm{Exp}}$ and Aldo ${ }^{\text {Exp}}$ ); between CK-MM of without LHD subjects (CK$\mathrm{MM}^{\mathrm{Con}}$ ) and AldoA of subjects without LHD (AldoA ${ }^{\mathrm{Con}}$ ); between CK-MM of subjects with LHD (CK-MM ${ }^{\mathrm{Exp}}$ ) and AldoA of subjects of without LHD $\left(\right.$ Aldo $\left.^{\text {Con }}\right)$ were all highly significant $(p<0.05)$ for both combined-sex patients. But Pearson's correlation coefficients: between subjects without LHD (CK-MM $\left.{ }^{\mathrm{Con}}\right)$ and CK-MM of subjects with LHD (CK-MM ${ }^{\mathrm{Exp}}$ ) and between AldoA of the subjects without LHD (Aldo ${ }^{\text {Con }}$ ) and AldoA with LHD (Aldo ${ }^{\text {Exp }}$ ) were not significant $(\mathrm{p}=0.076$, and $\mathrm{p}=0.137)$ respectively.

The percentage of increased/ decreased levels of the biomarkers such as IL-10, TNF- $\alpha$, CK-MM and AldoA for the subjects with LHD over the subjects without LHD were highly significant $(\mathrm{p}<0.0001)$ both overall and separately by gender and shown in Figure 1 .

\section{Anatomical parameters}

Figures 2-4 indicate that the mean \pm SD values of SLR and KFS while supine positions of the experimental subjects were all decreased and that were increased for KES while supine and observed to be all asymmetrical for both the legs. All the differences were highly significant $(\mathrm{p}<0.0001)$ when compared to the control subjects for both overall and separately by gender. [The data for SLRP, SLR Sit, KFP, KFSt., KEP and KESt are not shown].

Figures 5-9 emphasize the overall measurements of KGB, DAP, DBP, DCM and DTM were all increased/decreased and observed to be asymmetrical for both the legs of experimental subjects. The difference of mean \pm SD values of KGB, DAP and DBP for both the legs were extremely statistically significant $(\mathrm{p}<0.05)$ whereas the values of DCM and DTM were not significant for both right and left legs $(\mathrm{p}=0.104$ and $\mathrm{p}=0.0 .064 ; \mathrm{p}=0.068$ and $\mathrm{p}=0.139)$ respectively for combined-sex when compared with the control subjects.

\section{Dermatomes of the lower extremities}

Table 1: Demographic data and baseline characteristics of subjects.

\begin{tabular}{|c|c|c|}
\hline Characteristics & $\begin{array}{l}\text { Experimental } \\
\text { group }\end{array}$ & $\begin{array}{l}\text { Control } \\
\text { group }\end{array}$ \\
\hline No of subjects & 117 & 117 \\
\hline Females & $81(69.23 \%)$ & $81(69.23 \%)$ \\
\hline Age (yrs), [mean (SD)] & $59.84(7.17)$ & $58.86(7.62)$ \\
\hline Height (in m), [mean (SD)] & $1.55(0.71)$ & $1.51(0.78)$ \\
\hline Weight (in kg.), [mean (SD)] & $76.23(4.17)$ & $62.42(4.78)$ \\
\hline $\mathrm{BMI}\left(\mathrm{kg} / \mathrm{m}^{2}\right)[$ mean $(\mathrm{SD})]$ & $31.73(3.31)$ & $27.41(3.38)$ \\
\hline Period of suffering (yrs), [mean (SD)] & $5.88(1.92)$ & - \\
\hline \multicolumn{3}{|c|}{ 6Indian ethnic group (\%) } \\
\hline Bengali & $29(24.79)$ & $27(23.08)$ \\
\hline Gujrati & $11(9.40)$ & $13(11.11)$ \\
\hline Marwaree & $10(8.55)$ & $13(11.11)$ \\
\hline Marathi & $16(13.67)$ & $15(12.82)$ \\
\hline Tamil & $15(12.82)$ & $14(11.96)$ \\
\hline Punjabi & $13(11.11)$ & $12(10.26)$ \\
\hline Shindhi & $12(10.26)$ & $13(11.11)$ \\
\hline North East India & $11(9.40)$ & $10(8.55)$ \\
\hline \multicolumn{3}{|c|}{ Food habit (\%) } \\
\hline Vegetarian & $84(71.79)$ & $78(66.67)$ \\
\hline Non - vegetarian & $33(28.21)$ & $39(33.33)$ \\
\hline \multicolumn{3}{|c|}{ Other habits $(\%)$} \\
\hline Drinking excessive tea and coffee & $43(36.75)$ & $42(35.90)$ \\
\hline Smoking & $32(27.35)$ & $33(28.20)$ \\
\hline Drinking Alcohol & $31(26.50)$ & $30(25.64)$ \\
\hline Chewing tobacco & $11(9.40)$ & $12(10.26)$ \\
\hline \multicolumn{3}{|c|}{ Work status (\%) } \\
\hline Employed fulltime & $49(41.88)$ & $47(40.17)$ \\
\hline Employed part time & $11(9.40)$ & $10(8.55)$ \\
\hline Housewife / Homemaker & $12(10.26)$ & $14(11.96)$ \\
\hline Retired & $19(16.24)$ & $21(17.95)$ \\
\hline Self employed & $26(22.22)$ & $25(21.37)$ \\
\hline \multicolumn{3}{|c|}{ Multiple complaints (\%) } \\
\hline Constipation & $68(58.12)$ & $21(17.95)$ \\
\hline Acidity \& reflux & $72(61.54)$ & $17(14.53)$ \\
\hline 17Insomnia & $68(58.12)$ & $12(10.26)$ \\
\hline Varicose vein & $39(33.33)$ & $15(12.82)$ \\
\hline Urinary incontinence & $58(49.57)$ & $17(14.53)$ \\
\hline Crepitus during knee flexion & $3(2.56)$ & - \\
\hline Morning stiffness (<30 minute) & $27(23.08)$ & - \\
\hline \multicolumn{3}{|c|}{ Measures taken to diminish pain (\%) } \\
\hline Using a lumbar belt & $54(46.15)$ & - \\
\hline Under gone surgery & $18(15.38)$ & - \\
\hline Using a sick & $12(10.26)$ & - \\
\hline Using walker & $14(11.97)$ & - \\
\hline \multicolumn{3}{|c|}{ Oswestry Disability Index (ODI) (\%) } \\
\hline Minimal disability (0\% to $20 \%)$ & - & $117(100)$ \\
\hline Moderate disability ( $21 \%$ to $40 \%)$ & $1(0.85)$ & - \\
\hline Severe disability ( $41 \%$ to $60 \%)$ & $4(3.42)$ & - \\
\hline Crippled $(61 \%$ to $80 \%)$ & $91(77.78)$ & - \\
\hline $\begin{array}{l}\text { Bedridden or Exaggerating symptoms (81\% } \\
\text { to } 100 \%)\end{array}$ & $21(17.95)$ & - \\
\hline \multicolumn{3}{|c|}{ Lower Extremity Functional Scale (LEFS) (\%) } \\
\hline Unable to perform activity $(0)$ & $47((40.17)$ & - \\
\hline Quite a bit a difficulty (1) & $42(35.90)$ & - \\
\hline Moderate difficulty (2) & $26(22.22)$ & - \\
\hline A little bit of difficulty (3) & $2(1.71)$ & $18(15.38)$ \\
\hline No difficulty (4) & - & $99(84.62)$ \\
\hline
\end{tabular}


Citation: Ganguly A, Ganguly D. Aberrant Biomarkers, Leg Anatomy and Pain Parameters are the Risk Factors in Lumbar-Herniated Disc: a Novel Diagnostic Protocol. J Orthopedics Rheumatol. 2018; 5(2): 1

ISSN: $2334-2846$

Table 2: Statistical analysis of IL-10 \& TNF- $\alpha$ of 117 Experimental patients and 117 Control subjects.

\begin{tabular}{|c|c|c|c|c|c|c|c|}
\hline \multirow{3}{*}{ Biochemical parameter } & \multirow{3}{*}{ Gender } & \multirow{3}{*}{$\begin{array}{l}\text { Control Group } \\
\text { Mean (SD) }\end{array}$} & \multirow{3}{*}{$\begin{array}{c}\text { Experimental Group } \\
\text { Mean (SD) }\end{array}$} & \multicolumn{4}{|c|}{ Differential level of biomarker over control group } \\
\hline & & & & \multirow{2}{*}{ MD } & \multicolumn{2}{|c|}{$95 \% \mathrm{Cl}$ of difference } & \multirow{2}{*}{ P-value } \\
\hline & & & & & Lower limit & Upper limit & \\
\hline \multirow{3}{*}{$\mathrm{IL}-10(\mathrm{pg} / \mathrm{ml})$} & $\begin{array}{c}\text { Combined-sex } \\
\left(\mathrm{N}_{\mathrm{e}}=117 \& \mathrm{~N}_{\mathrm{c}}=117\right)\end{array}$ & $\begin{array}{l}18.34 \\
-2.63\end{array}$ & $\begin{array}{l}7.84 \\
-1.4\end{array}$ & 10.5 & 9.96 & 11.04 & $<0.0001$ \\
\hline & $\begin{array}{c}\text { Female-only } \\
\left(N_{e}=36 \& N_{c}=36\right)\end{array}$ & $\begin{array}{l}17.93 \\
-2.64\end{array}$ & $\begin{array}{l}7.95 \\
-1.4\end{array}$ & 9.98 & 8.99 & 10.97 & $<0.0001$ \\
\hline & $\begin{array}{c}\text { Male-only } \\
\left(\mathrm{N}_{\mathrm{e}}=81 \& \mathrm{~N}_{\mathrm{c}}=81\right)\end{array}$ & $\begin{array}{l}18.48 \\
-2.63\end{array}$ & $\begin{array}{c}7.8 \\
-1.41\end{array}$ & 10.68 & 10.02 & 11.34 & $<0.0001$ \\
\hline \multirow{3}{*}{ TNF- $\alpha(p g / m l)$} & $\begin{array}{c}\text { Combined-sex } \\
\left(N_{e}=117 \& N_{c}=117\right)\end{array}$ & $\begin{array}{l}11.96 \\
-1.76\end{array}$ & $\begin{array}{l}27.04 \\
-5.16\end{array}$ & -15.08 & -16.11 & -14.05 & $<0.0001$ \\
\hline & $\begin{array}{c}\text { Female-only } \\
\left(\mathrm{N}_{\mathrm{e}}=36 \& \mathrm{~N}_{\mathrm{c}}=36\right)\end{array}$ & $\begin{array}{l}11.61 \\
-1.32\end{array}$ & $\begin{array}{l}26.18 \\
-3.69\end{array}$ & -14.57 & -16.69 & -13.27 & $<0.0001$ \\
\hline & $\begin{array}{c}\text { Male-only } \\
\left(N_{e}=81 \& N_{c}=81\right)\end{array}$ & $\begin{array}{l}12.08 \\
-1.23\end{array}$ & $\begin{array}{l}27.42 \\
-5.67\end{array}$ & -15.34 & -16.69 & -13.99 & $<0.0001$ \\
\hline
\end{tabular}

Table 3: Analysis of ratio of IL-10 and TNF- $\alpha$ of 117 experimental patients and 117 control subjects.

\begin{tabular}{|c|c|c|c|c|c|c|}
\hline \multirow[b]{2}{*}{ Gender } & \multirow{2}{*}{$\begin{array}{c}\text { Control } \\
\text { Group } \\
\text { IL-10: } \\
\text { TNF- } \alpha \\
\text { Mean (SD) }\end{array}$} & \multirow{2}{*}{$\begin{array}{c}\begin{array}{c}\text { Experimental } \\
\text { Group }\end{array} \\
\text { IL-10: } \\
\text { TNF- } \alpha \\
\text { Mean (SD) } \\
\end{array}$} & \multicolumn{4}{|c|}{ Elevated levels over control group } \\
\hline & & & $p$-value & MD & \multicolumn{2}{|c|}{$95 \% \mathrm{CI}$} \\
\hline $\begin{array}{c}\text { Combined-sex } \\
\left(\mathrm{N}_{\mathrm{e}}=117 \& \mathrm{~N}_{\mathrm{c}}=117\right)\end{array}$ & $\begin{array}{r}1.55 \\
-0.29\end{array}$ & $\begin{array}{c}0.3 \\
-0.08\end{array}$ & $<0.0001$ & 1.25 & 1.2 & 1.3 \\
\hline $\begin{array}{c}\text { Female-only } \\
\left(\mathrm{N}_{\mathrm{e}}=36 \& \mathrm{~N}_{\mathrm{c}}=36\right)\end{array}$ & $\begin{array}{r}1.57 \\
-0.33\end{array}$ & $\begin{array}{c}0.31 \\
-0.06\end{array}$ & $<0.0001$ & 1.26 & 1.15 & 1.37 \\
\hline $\begin{array}{c}\text { Male-only } \\
\left(N_{e}=81 \& N_{c}=81\right)\end{array}$ & $\begin{array}{r}1.55 \\
-0.28\end{array}$ & $\begin{array}{c}0.3 \\
-0.08\end{array}$ & $<0.0001$ & 1.25 & 1.18 & 1.31 \\
\hline
\end{tabular}

Table 4: Statistical analysis of biochemical parameters of 117 experimental and 117 control subjects.

\begin{tabular}{|c|c|c|c|c|c|c|c|}
\hline \multirow{3}{*}{ Biochemical parameter } & \multirow{3}{*}{ Gender } & \multirow{3}{*}{$\begin{array}{c}\text { Control } \\
\text { Mean (SD) }\end{array}$} & \multirow{3}{*}{$\begin{array}{c}\text { Experimental Group } \\
\text { Mean (SD) }\end{array}$} & \multicolumn{4}{|c|}{ Elevated levels of biomarkers } \\
\hline & & & & \multirow{2}{*}{ MD } & \multicolumn{2}{|c|}{$95 \% \mathrm{Cl}$ of difference } & \multirow{2}{*}{ p-value } \\
\hline & & & & & Lower & Upper & \\
\hline \multirow{3}{*}{ CK-MM (U/L) } & $\begin{array}{c}\text { Combined-sex } \\
\left(N_{\mathrm{e}}=117 \& \mathrm{~N}_{\mathrm{c}}=117\right)\end{array}$ & $\begin{array}{c}85.7 \\
-23.69\end{array}$ & $\begin{array}{c}189.05 \\
-58.9\end{array}$ & -103.35 & -115.39 & -91.31 & $<0.0001$ \\
\hline & $\begin{array}{c}\text { Female-only } \\
\left(\mathrm{N}_{\mathrm{e}}=36 \& \mathrm{~N}_{\mathrm{c}}=36\right)\end{array}$ & $\begin{array}{c}83.18 \\
-21.95\end{array}$ & $\begin{array}{l}204.8 \\
-71.17\end{array}$ & -121.63 & -140.38 & -96.86 & $<0.0001$ \\
\hline & $\begin{array}{c}\text { Male-only } \\
\left(\mathrm{N}_{\mathrm{e}}=81 \& \mathrm{~N}_{\mathrm{c}}=81\right)\end{array}$ & $\begin{array}{c}87 \\
-24.56\end{array}$ & $\begin{array}{c}181.2 \\
-50.43\end{array}$ & -94.2 & -107.27 & -81.13 & $<0.0001$ \\
\hline \multirow{3}{*}{ AldoA (U/L) } & $\begin{array}{c}\text { Combined-sex } \\
\left(\mathrm{N}_{\mathrm{e}}=117 \& \mathrm{~N}_{\mathrm{c}}=117\right)\end{array}$ & $\begin{array}{c}4.94 \\
-1.06 \\
\end{array}$ & $\begin{array}{l}8.08 \\
-1.94\end{array}$ & -3.14 & -3.56 & -2.72 & $<0.0001$ \\
\hline & $\begin{array}{c}\text { Female-only } \\
\left(\mathrm{N}_{\mathrm{e}}=36 \& \mathrm{~N}_{\mathrm{c}}=36\right)\end{array}$ & $\begin{array}{r}4.86 \\
-1.09\end{array}$ & $\begin{array}{l}8.28 \\
-2\end{array}$ & -3.42 & -4.17 & -2.66 & $<0.0001$ \\
\hline & $\begin{array}{c}\text { Male-only } \\
\left(\mathrm{N}_{\mathrm{e}}=81 \& \mathrm{~N}_{\mathrm{c}}=81\right)\end{array}$ & $\begin{array}{c}5 \\
-1.04\end{array}$ & $\begin{array}{c}8 \\
-1.92\end{array}$ & -3 & -3.51 & -2.49 & $<0.0001$ \\
\hline
\end{tabular}

Table 5: Analysis of ratio of CK-MM and Aldo A of 117 experimental patients and 117 control subjects.

\begin{tabular}{|c|c|c|c|c|c|c|}
\hline \multirow[b]{2}{*}{ Gender } & \multirow{2}{*}{ 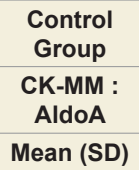 } & \multirow{2}{*}{$\begin{array}{c}\begin{array}{c}\text { Experimental } \\
\text { Group }\end{array} \\
\text { CK-MM : AldoA } \\
\text { Mean (SD) }\end{array}$} & \multicolumn{4}{|c|}{ Elevated levels over control group } \\
\hline & & & p-value & MD & \multicolumn{2}{|c|}{$95 \% \mathrm{Cl}$} \\
\hline $\begin{array}{c}\text { Combined-sex } \\
\left(N_{e}=117 \& N_{c}=117\right)\end{array}$ & $\begin{array}{l}17.9 \\
-5.6\end{array}$ & $\begin{array}{r}25.23 \\
-10.59 \\
\end{array}$ & $<0.0001$ & -7.3 & -9.6 & -5.06 \\
\hline $\begin{array}{c}\text { Female-only } \\
\left(N_{e}=36 \& N_{c}=36\right)\end{array}$ & $\begin{array}{l}17.72 \\
-5.23\end{array}$ & $\begin{array}{l}26.73 \\
-11.95\end{array}$ & $<0.0001$ & -9.01 & -13.35 & -4.67 \\
\hline $\begin{array}{c}\text { Male-only } \\
\left(\mathrm{N}_{\mathrm{e}}=81 \& \mathrm{~N}_{\mathrm{c}}=81\right)\end{array}$ & $\begin{array}{c}18 \\
-5.81\end{array}$ & $\begin{array}{l}24.49 \\
-9.84\end{array}$ & $<0.0001$ & -6.49 & -9.15 & -3.83 \\
\hline
\end{tabular}


Citation: Ganguly A, Ganguly D. Aberrant Biomarkers, Leg Anatomy and Pain Parameters are the Risk Factors in Lumbar-Herniated Disc: a Novel Diagnostic Protocol. J Orthopedics Rheumatol. 2018; 5(2): 1

ISSN: 2334-2846

Table 6: Analysis of person's correlation coefficients between two biomarkers.

\begin{tabular}{|c|c|c|c|c|c|c|c|c|c|c|}
\hline \multirow[t]{2}{*}{ Gender } & \multicolumn{2}{|c|}{$\begin{array}{l}\text { IL-10 Con } \\
\text { and } \\
\text { IL-10 }\end{array}$} & \multicolumn{2}{|c|}{$\begin{array}{l}\text { TNF- } \alpha^{\text {Con }} \\
\text { and } \\
\text { TNF- } \alpha^{\operatorname{Exp}}\end{array}$} & \multicolumn{2}{|c|}{$\begin{array}{c}\text { IL-10 }{ }^{\operatorname{Exp}} \\
\text { and } \\
\text { TNF- } \alpha^{\operatorname{Exp}}\end{array}$} & \multicolumn{2}{|c|}{$\begin{array}{l}\text { IL-10 } \\
\text { and } \\
\text { TNF- } \alpha^{\text {Con }}\end{array}$} & \multicolumn{2}{|c|}{$\begin{array}{c}\text { IL-10 } \\
\text { and } \\
\text { TTNF- } \alpha^{\text {Con }}\end{array}$} \\
\hline & R-value & $p$-value & R-value & $p$-value & R-value & $p$-value & R-value & $p$-value & R-value & $p$-value \\
\hline $\begin{array}{c}\text { Female-only } \\
\left(\mathrm{N}_{\mathrm{e}}=36 \& \mathrm{~N}_{\mathrm{c}}=36\right)\end{array}$ & -0.297 & 0.078 & -0.13 & 0.419 & 0.017 & 0.919 & -0.199 & 0.243 & 0.342 & 0.038 \\
\hline $\begin{array}{c}\text { Male-only } \\
\left(\mathrm{N}_{\mathrm{e}}=81 \& \mathrm{~N}_{\mathrm{c}}=81\right)\end{array}$ & -0.147 & 0.218 & 0.176 & 0.14 & -0.108 & 0.365 & -0.15 & 0.207 & -0.021 & 0.863 \\
\hline
\end{tabular}

Table 7: Analysis of person's correlation coefficients between two biomarkers.

\begin{tabular}{|c|c|c|c|c|c|c|c|c|c|c|}
\hline \multirow[t]{2}{*}{ Gender } & \multicolumn{2}{|c|}{$\begin{array}{l}\text { CK-MM } M^{\text {Con }} \\
\text { and } \\
\text { CK-MMMEx }\end{array}$} & \multicolumn{2}{|c|}{$\begin{array}{l}\text { Aldo }^{\text {con }} \\
\text { and } \\
\text { Aldo }^{\operatorname{Exp}}\end{array}$} & \multicolumn{2}{|c|}{$\begin{array}{l}\text { CK-MM }{ }^{\operatorname{Exp}} \\
\text { and } \\
\text { AldoA }^{\operatorname{Exp}}\end{array}$} & \multicolumn{2}{|c|}{$\begin{array}{l}\text { CK-MM } M^{\text {Con }} \\
\text { and } \\
\text { AldoA }^{\text {con }}\end{array}$} & \multicolumn{2}{|c|}{$\begin{array}{l}\text { CK-MM }{ }^{\operatorname{Exp}} \\
\text { and } \\
\text { AldoA }^{\text {Con }}\end{array}$} \\
\hline & R-value & p-value & R-value & p-value & R-value & p-value & R-value & p-value & R-value & p-value \\
\hline Combined-sex $\left(\mathrm{N}_{\mathrm{e}}=117 \& \mathrm{~N}_{\mathrm{c}}=117\right)$ & -0.171 & 0.076 & 0.144 & 0.137 & -0.434 & 0 & 0.245 & 0.011 & -0.197 & 0.041 \\
\hline $\begin{array}{c}\text { Female-only } \\
\left(\mathrm{N}_{\mathrm{e}}=36 \& \mathrm{~N}_{\mathrm{c}}=36\right)\end{array}$ & -0.214 & 0.21 & 0.121 & 0.482 & -0.441 & 0.007 & 0.256 & 0.131 & -0.179 & 0.296 \\
\hline $\begin{array}{c}\text { Male-only } \\
\left(\mathrm{N}_{\mathrm{e}}=81 \& \mathrm{~N}_{\mathrm{c}}=81\right)\end{array}$ & -0.137 & 0.25 & 0.164 & 0.167 & -0.454 & 0.005 & 0.226 & 0.056 & -0.209 & 0.079 \\
\hline
\end{tabular}

Table 8: Location of pain, sensory loss and weakness in association with compression of nerve roots during herniated disc in the Lumbar region.

\begin{tabular}{|c|c|c|c|}
\hline Nerve & Location of pain & Sensory loss on & Weakness on \\
\hline L1 & Inguinal and medial thigh & Inguinal region & Flexion weakness is rare \\
\hline L2,L3-L4 & $\begin{array}{c}\text { Back pain radiating into the anterior and } \\
\text { medial aspect of upper thigh and medial } \\
\text { lower leg. }\end{array}$ & $\begin{array}{c}\text { Anterior thigh and sometimes } \\
\text { medial lower leg }\end{array}$ & Hip flexion and adduction, knee extension and quadriceps. Diminished patella \\
reflex.
\end{tabular}

Table 9: KL grading scale for disc degenerative.

\begin{tabular}{|l|c|c|c|c|}
\hline \multirow{2}{*}{} & \multicolumn{2}{|c|}{ Experimental Group } & \multicolumn{2}{c|}{ Control Group } \\
\cline { 2 - 5 } & No of Patient & Percentage & No of Patient & Percentage \\
\hline Grade 1: & None & None & 108 & 92.31 \\
\hline Grade 2: & None & None & 9 & 7.69 \\
\hline Grade 3: & 75 & 64.1 & - & - \\
\hline Grade 4: & 42 & 35.9 & - & - \\
\hline
\end{tabular}

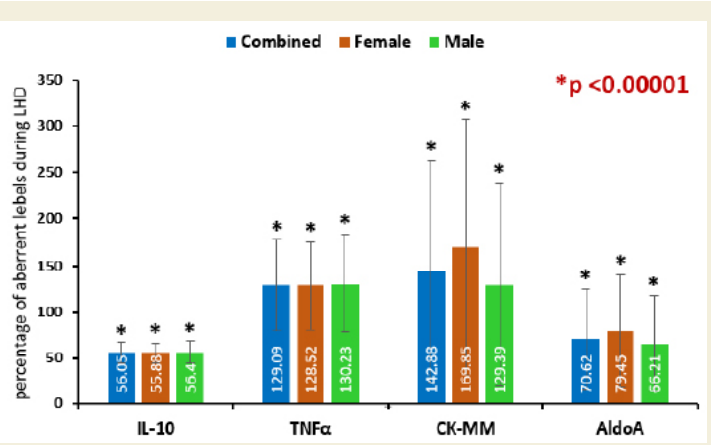

Figure 1: Percentage of aberrant levels of biomarkers of experimental subjects over control subjects during LHD $\left({ }^{*} p<0.0001\right)$.
Other reasons for measuring the above-mentioned deranged anatomical parameters were to identify the damages occur during LHD as these can be distinctly marked in the dermatomal picture shown in Figure 10 and details of the location of pain, sensory loss and weakness due to motor deficit in association with the nerve root involvement of each lumbar disc level shown in Table 8.

\section{Performance status, Back pain related parameters and BMI}

The percentage of increased levels of pain on right leg, left leg and lower back of the experimental subjects for combined-sex, femaleonly and male-only patients separately evaluated under VAS was highly significant difference $(\mathrm{p}<0.05)$ over the control subjects both overall and separately by gender and depicted in Figure 11.

The percentages of decreased levels on the performance on daily activities under KPS, status of the patient specific functional and disability separately as assessed under the scales LEFS and ODI and body weight confirmed by BMI of the subjects of experimental group compared to the subjects of control group were all highly significant differences $(\mathrm{p}<0.0001)$ and shown in Figure12.

Analysis of radiological images as assessed by K-L grading scale

All the lateral views of the X-rayed of 117 patients with LHD 
Citation: Ganguly A, Ganguly D. Aberrant Biomarkers, Leg Anatomy and Pain Parameters are the Risk Factors in Lumbar-Herniated Disc: a Novel Diagnostic Protocol. J Orthopedics Rheumatol. 2018; 5(2): 1

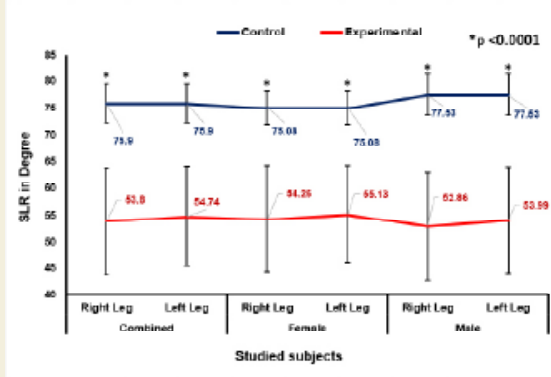

Figure 2: Graphical representation of abnormal SLR parameters with asymmetry between the right and left legs of experimental patients and that are symmetrical for control subjects $\left({ }^{*} p<0.0001\right)$.

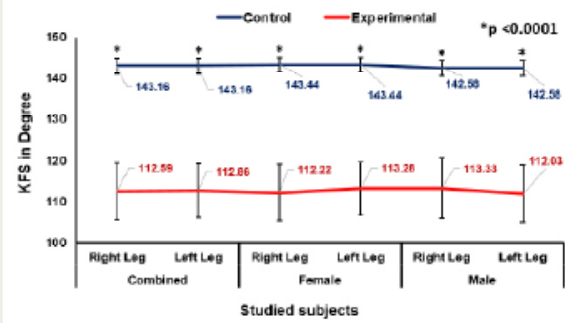

Figure 3: Graphical representation of abnormal KFS parameters with asymmetry between the right and left legs of experimental patients and that are symmetrical for control subjects $\left({ }^{*} p<0.0001\right)$

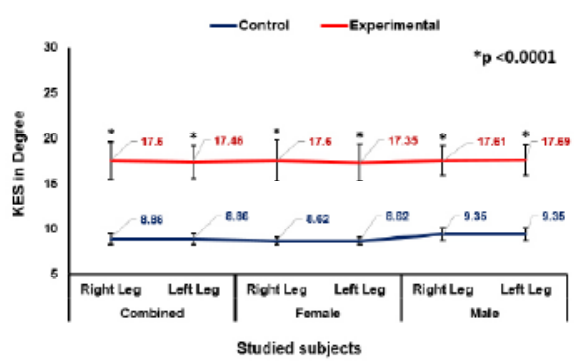

Figure 4: Graphical representation of abnormal KES parameters with asymmetry between the right and left legs of experimental patients and that are symmetrical for control subjects $\left({ }^{*} p<0.0001\right)$.

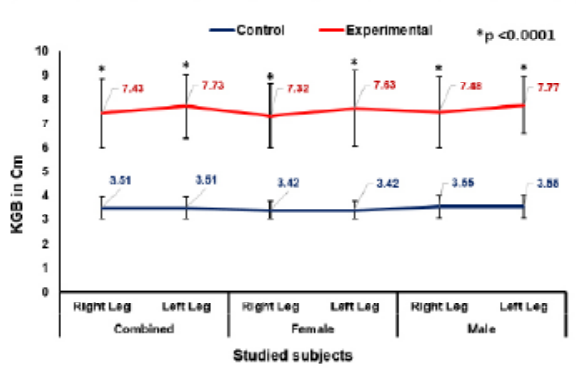

Figure 5: Graphical representation of abnormal KGB parameters with asymmetry between the right and left legs of experimental patients and that are symmetrical for control subjects $\left({ }^{*} p<0.0001\right)$.

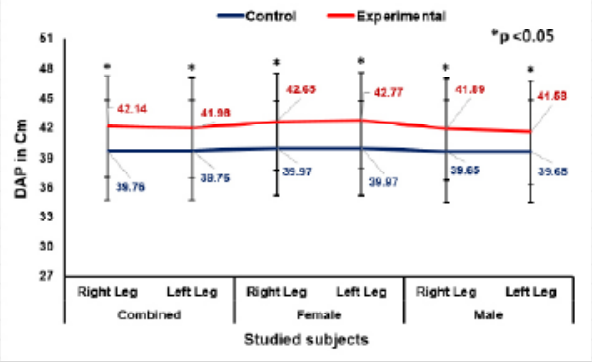

Figure 6: Graphical representation of abnormal DAPS parameters with asymmetry between the right and left legs of experimental patients and that are symmetrical for control subjects $\left({ }^{*} p<0.05\right)$.

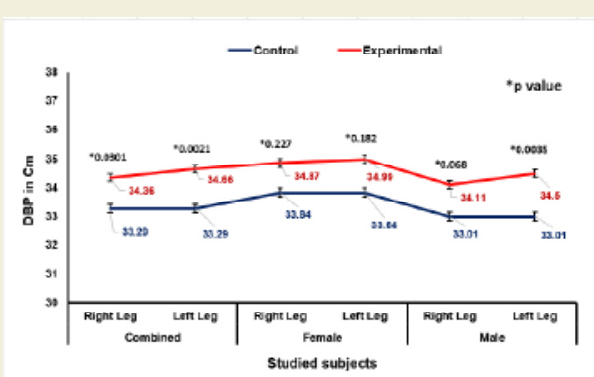

Figure 7: Graphical representation of abnormal DBP parameters with asymmetry between the right and left legs of experimental patients and that are symmetrical for control subjects.

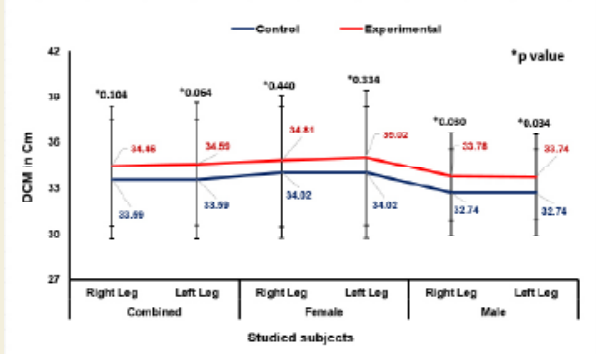

Figure 8: Graphical representation of abnormal DCM parameters with asymmetry between the right and left legs of experimental patients and that are symmetrical for control subjects.

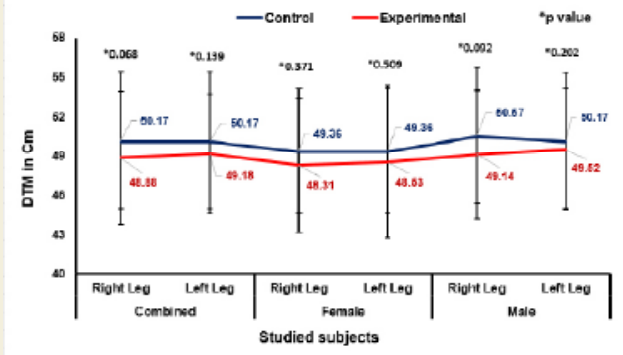

Figure 9: Graphical representation of abnormal DTM parameters with asymmetry between the right and left legs of experimental patients and that are symmetrical for control subjects 


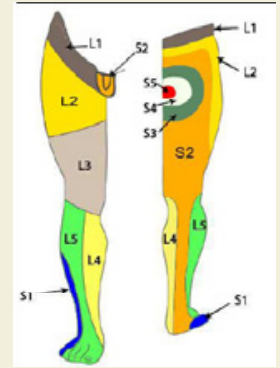

Figure 10: Dermatomes of Lower Limb effecting pain, numbness, muscular deformities etc during LHD.

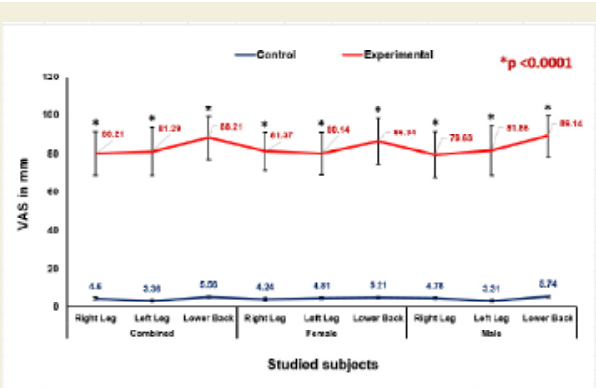

Figure 11: Graphical representation of abnormal VAS parameters with asymmetry between the right and left legs of experimental patients and that are symmetrical for control subjects $\left({ }^{*} p<0.0001\right)$.

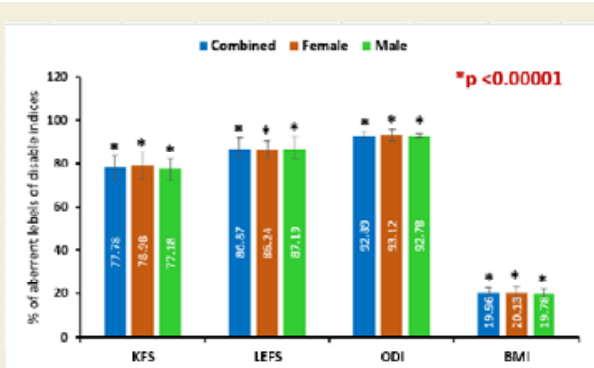

Figure 12: Percentage of increased levels of pain and disability parameters under acclaimed international outcomes along with BMI of experimental subjects over control subject ( $\left.{ }^{*} p<0.0001\right)$.

exhibited degenerative changes, particularly at the region of one or more of the intervertebral levels of L1-L2 to L5-S1 with marked disk narrowing and osteophytes formation. Some cases exhibited bone sclerosis, disc space narrowing and large osteophytes. The lateral views of X-rayed of the lumbar vertebrae of the cohorts without LHD were observed no such narrowing of dice and osteophytes formation and their assessment under K-L grading scale are shown in Table-9.

\section{Discussion}

In the present study, it was suggested the novel diagnostic protocol to detect the LHD evidenced by the aberrant anatomical features, anamalous levels of biomarkers such as IL-10, TNF- $\alpha$, CK$\mathrm{MM}$ and AldoA and abnormal indices values on pain parameters, functional disabilities and obesity as per international acclaimed outcome measurements along with radiological images as assessed by KL grading scale as cost-effective diagnostic protocol compared to MRI or CT scan or Discogram or Myelogram and others tools as costly affairs especially in developing countries like India [44-48]. From past, the main diagnostic tool for detecting LHD is MRI or X-ray $[8,11-17]$.

Although, MRI is the gold standard for evaluating the relationship of disc material to soft tissue and neural structures. But the main issue in the management of patients with lumbar disc disease and nerve root compression is correlation of imaging findings with clinical presentation and symptomatology to guide treatment and intervention [8]. Moreover, the researchers have already highlighted that the various nerve roots compression during LHD cannot be diagnosed with the help of MRI [18]. Therefore, the causing factors of compressed nerve roots such as inflammation, pain, numbness or weakness in the lower extremities along with deranged anatomical features which are developed simultaneously during LHD cannot be identified with the help of MRI, in addition to that MRI has certain critical limitations such as metal objects implanted in the body viz. pacemakers, prosthetic joints, rods and certain tattoos and restricted to overweight, very tall and claustrophobic patients and at the same time diagnosis of LHD through Discogram or Myelogram cannot emphasize either muscle weakness and numbness nor inflammatory status.

Again, in case of X-ray, LHD can be identified only in advance stage for assessing the condition of bones at musculoskeletal joints of lumbar vertebrae such as slight anterior wear and osteophytes formation, definite anterior wear and osteophytes formation, osteophytes formation and narrowing of disc, large osteophytes, marked disc narrowing, sclerosis of vertebral plates and posterior subluxation by using lateral radiographs of the lumbar spine by four graded scale developed by Kellgrenand Lawrence but definite quantum of inflammation, muscle degeneration and skeletal muscle damage affecting damage of IVD cannot be identified from X-ray images [42].

The results from the deranged anatomical parameters shows that there are substantial increasing and decreasing phenomenon of the group of muscles connected with various joints and both the legs were asymmetrical in respect of the measurements of KGB, DAP, DBP, DCM, DTM, SLR, KFS and KES of the experimental cohorts which indicate the muscular wasting, muscle weakness and degeneration that were occurred during LHD.

It is interesting to note that abnormal anatomical features can be potent diagnostic tool to detect LHD. Ganguly showed in the previous research work that degenerative changes in lumbar region always lead to bilateral degenerative changes in knee-joints and vice-versa [21]. According to him, LHD can be correlated to abnormal anatomy of musculo-skeletal features of both legs (unpublished). In this context, researchers have studied only ROM at lumbar region [19-20].In recent research, MRI and X-ray revealed the biomechanical abnormalities such as Pfirrmann grade of IVD degeneration, discheight index, segmental sagittal range of motions, central angle of lumbar lordosis, Modic criteria, herniation type, presence of listhesis of the lumbar spine instead of abnormal anatomical features of legs [48]. These parameters may not be cost-effective for the patients of developing country like India. Ganguly and had already been investigated cost- 
Citation: Ganguly A, Ganguly D. Aberrant Biomarkers, Leg Anatomy and Pain Parameters are the Risk Factors in Lumbar-Herniated Disc: a Novel Diagnostic Protocol. J Orthopedics Rheumatol. 2018; 5(2): 1

effective abnormal musculo-skeletal parameters such as KGB, DAP, DBP, DCM, DTM, SLR, KFS and KES, which has close similarities in respect to flexion and extension parameters in earlier studies $[27,28,36,49-52]$.

In case of biochemical parameters, the elevated levels of IL-10, TNF- $\alpha$, CK-MM, and AldoA observed in patients with LHD have confirmed that these biomarkers are predictive risk factors that may be monitored and serve as one of the best diagnostic protocols quickly and in affordable low-cost even in the early progressive stage of LHD where there is no pain syndrome or discomfort or deformities observed in the lower extremities or joints confirmed with X-rays or MRI images only at advance stage but not in early progressive stage. It has been studied that the quantitative and qualitative characteristics of proteoglycans/glycosaminoglycans of the nucleus pulposus and annulus fibrosus from IVD tissues of LHD patients through microdiscectomy, which may also be costly affair [48]. Patho-physiologically, LHD has been established by the combination of the mechanical compression of the nerve resulted with the bulging nucleus pulposus and the local elevated level of inflammatory chemokines (small cytokines).

Generally, cytokines are small, hormone-like, signal peptides produced in cells activated by inflammatory agents. The TNF- $\alpha$ is a pro-inflammatory cytokine and IL-10 is an anti-inflammatory cytokine. The balance between TNF- $\alpha$ (standard value $<15 \mathrm{pg} / \mathrm{ml}$ ) and IL-10 (standard value $>12 \mathrm{pg} / \mathrm{ml}$ ) is important for immune homeostasis maintenance. Exuberant production of TNF- $a$ contributes to overwhelming inflammatory response and tissue damage. At the same time, IL-10 is known as human Cytokine Synthesis Inhibitory Factor (CSIF) and it is an anti-inflammatory cytokine. Therefore, it is capable of inhibiting synthesis of proinflammatory cytokine (TNF- $\alpha$ ) expression and release from alveolar macrophages and peripheral blood monocytes. Increase in TNF- $\alpha$ is counter balanced by simultaneous synthesis of an anti-inflammatory cytokine IL-10, which suppresses production of many activating and regulatory mediators. Due to a decrease in IL-10 levels, TNF- $\alpha$ levels are not regulated effectively as IL-10 regulates the TNF- $\alpha$ converting enzyme. Inflammatory processes exacerbated by cytokines TNF- $\alpha$ and IL-10 is believed to be key mediators of IVD degenerative disease like LHD. It is well-known that degeneration of the intervertebral disc is characterized by an elevation in levels of the inflammatory cytokines tumor necrosis factor (TNF)- $\alpha$, interleukin (IL)- $1 \alpha / \beta$ IL-6 and IL-17 secreted by the disc cells themselves; these cytokines promote matrix degradation, chemokine production and changes in cell phenotype [53]. According to Séguin et al. TNF- $\alpha$ over expression in nucleus pulposus tissues was reported during disc degeneration. Among other common mediators of inflammation, IL-10 is also a suitable parameter to detect disc herniation $[54,55]$.

Besides these anatomical features and biochemical parameters, different indices of pain, functional disabilities and obesity are also suitable diagnostic tools, which found abnormal results in the present study of the experimental group. According to several researcher's different indices such as VAS, KPS, LEFS, and ODI as well as obesity (BMI) have been well-established in joint disorders [37-41,56]. In the present study, it was observed that these parameters can be suitable to diagnose LHD.
Moreover, all the tests can be done easily with minimum cost. However, a combined approach using all these biomarkers to detect risk factors for LHD has not so far been attempted. The present study has found triangular approach such abnormal anatomy of musculoskeletal features with radiography (KL grading scale), aberrant levels of biochemical parameters and pain, functional disabilities and obesity indices with dermatomes in a combined form can be confirmed as an affordable low-cost diagnostic tool for LHD not yet identified till date.

\section{Conclusion}

It is firmly concluded that monitoring the aberrant biomarkers such as IL-10, TNF- $\alpha$, CK-MM and AldoA and measurements of deranged lower extremities viz. KGB, DTM, DCM, SLR, KFS and KES along with International acclaimed functional disability outcome parameters (VAS, KPS, LEFS, ODI and BMI) confirming with spine radiographic images as assessed by the KL grading scale may be the novel diagnostic protocol for detecting LHD at minimum cost and time.

\section{References}

1. Heliovaara M (1989) Risk factors for low back pain and sciatica. Ann Med 21: $257-264$.

2. Wu ZS, Zhen S, Wang TY, Ye SB (2003) Surgery ( $5^{\text {th }}$ edn). In: Beijing: Ren Min Wei Sheng Chu Ban She 875-878.

3. Pan HJ (2002) Biomechanics analysis on lumbar intervertebral nucleus pulposus outstanding disease. China J Spor Med 21: 138-140.

4. Freynhagen R, Baron R, Gockel U, Tolle TR (2006) PainDETECT: A new screening questionnaire to identify neuropathic components in patients with back pain. Curr Med Res Opin 22: 1911-1920.

5. Hoy D, Bain C, Williams G, March L, Brooks P, et al. (2012) A systematic review of the global prevalence of low back pain. Arthritis Rheum 64: 20282037.

6. Chen R, Xiong J, Chi Z, Zhang B (2012) Heat-sensitive moxibustion for lumbar disc herniation: a meta-analysis of randomized controlled trials. J Tradit Chin Med 32: 322-328.

7. Jain N (2013) Slip disc with sciatica-Newer non-surgical treatment. JIMSA 26: $249-251$

8. Li Y, Fredrickson V, Resnick DK (2015) How should we grade Lumbar disc herniation and nerve root compression? A systematic review. Clin Orthop Relat Res 473: 1896-1902.

9. Lawrence JS (1969) Disc degeneration. Its frequency and relationship to symptoms, Ann Rheum Dis 28: 121-138.

10. Schmorl G, Junganns H (1951) Die gesunde und kranke Wirbelsaule in Rontgenbild und Klinik. Gebundenes Buch.

11. Begg AC, Falconer MA (1949) Plain radiography in intraspinal protrusion of lumbar intervertebral discs: a correlation with operative findings. $\mathrm{Br} \mathrm{J}$ Surg 36: 225-239.

12. Hadley LA (1964) Anatomico-roentgenographic studies of the spine. In: Thomas (1 ${ }^{\text {st }}$ Eds). pp. 545.

13. Penning L, Blickman JR (1980) Instability in lumbar spondylolisthesis: A radiologic study of several concepts. AJR Am J Roentgenol 134: 293-301.

14. Tertti MO, Salminen JJ, Paajanen HEK, Terho PH, Kormano MJ (1991) Low-back pain and disc degeneration in children: a case-control MR imaging study. Radiology 180: 503-507.

15. Kumar VS (2005) Total clinical and radiological resolution of acute, massive Lumbar disc prolapses by ozonucleolysis. Rivista Italiana di Ossigenoozonoterapia 4: 104-106. 
Citation: Ganguly A, Ganguly D. Aberrant Biomarkers, Leg Anatomy and Pain Parameters are the Risk Factors in Lumbar-Herniated Disc: a Novel Diagnostic Protocol. J Orthopedics Rheumatol. 2018; 5(2): 1

ISSN: 2334-2846

16. Koes BW, van Tulder MW, Peul WC (2007) Diagnosis and treatment of sciatica. BMJ 334: 1313-1317

17. Karahan A, Kav S, Abbasoglu A, Cogan N (2009) Low back pain: Prevalence and associated risk factors among hospital staff. J Adv Nurs 65: 516-524.

18. Chawalparit $O$, Churojana A, Chiewvit $P$, Thanapipatsir $S$, Vamvanij $V$, et al (2006) The limited protocol MRI in diagnosis of lumbar disc herniation. J Med Assoc Thai 89:182-190.

19. Debrunner HU (1972) The Kyphometer. Z Orthop Ihre Grenzgeb 110: 389 392

20. Vucetic N, Svensson O (1996) Physical signs in lumbar disc hernia. Clin Orthop Relat Res 333: 192-201.

21. Ganguly A (2015) Degenerative changes in lumbar region always lead to bilateral degenerative changes in knee-joints and vice-versa: Sensation of pain cannot only be the parameter of degeneration. Anat Physol S4: 005.

22. Apple FS, Hellsten Y, Ciarkson PM (1988) Early detection of skeletal muscle injury by assay of creatine kinase MM isoforms in Serum. Clin Chem 34 $1102-1104$.

23. Platzer C, Meisel C, Vogt K, Platzer M, Volk HD (1995) Up-regulation of monocytic IL-10 by tumor necrosis factor-alpha and cAMP elevating drugs. Int Immunol 7: 517-523.

24. Kusakabe T, Motoki K, Hori K (1997) Mode of interactions of human aldolase isozymes with cytoskeletons. Arch Biochem Biophys 344: 184-193.

25. Botha-Scheepers S, Watt I, Slagboom E, de Craen AJ, Meulenbelt I, et al. (2008) Innate production of tumour necrosis factor a and interleukin 10 is associated with radiological progression of knee osteoarthritis. Ann Rheum Dis 67: 1165-1169.

26. Ouyang W, Rutz S, Crellin NK, Valdez PA, Hymowitz SG (2011) Regulation and functions of the IL-10 family of cytokines in inflammation and disease. Annu Rev Immunol 29: 71-109.

27. Ganguly A (2017) Diagnosis, prevention \& phytotherapy for osteoarthritic disorders. Pain diagnostic parameters and prevention of OADs. Scholars Press Book. pp. 84

28. Ganguly A (2018) Levels of C-reactive protein, creatine kinase-muscle and aldolase $A$ are suitable biomarkers for detecting risk factors for osteoarthritic disorders: A novel diagnostic protocol. Caspian J Int Med.

29. White AA, Panjabi MM (1990) Clinical biomechanics of the spine. In: ( $\left.2^{\text {nd }} e d n\right)$ Auszug: Seite 18 und 19 pp. 1-3.

30. Katz JN, Chang LC, Sangha O, Fossel AH, Bates DW (1996) Can comorbiditybe measured by questionnaire rather than medical record review? Med Care 34: 73-84

31. Singh B, Bhaya M, Stern J, Roland JT, Zimbler M, et al. (1997) Validation of the Charlson co-morbidity index in patients with head and neck cancer: amulti-institutional study. Laryngoscope 107: 1469-1475.

32. VilcekJ, Lee TH (1991) Tumor necrosis factor, New insights into the molecular mechanisms of its multiple actions. J Biol Chem 266: 7313-7316.

33. Gesser B, Leffers H, Jinquan T, Vestergaard C, Kirstein N, et al. (1997) Identification of functional domains on human interleukin 10. Proc Natl Acad Sci U S A 94: 14620-14625.

34. Cabaniss C (1990) In clinical methods ( $3^{\text {rd }}$ edn). In: Walker HK, Hall WD Hurst JW (Eds) The history, physical, and laboratory examinations. Clin Methods 161-163.

35. Feissli S (1966) Quantitative determination of Aldolase. Klin Wschr 44: 390.

36. American Academy of Orthopaedic Surgeons (AAOS) (1965) Joint motion: Method of measuring and recording, Chicago.

37. Bodian CA, Freedman G, Hossain S, Eisenkraf JB, Beilin Y (2001) The visual analog scale for pain: clinical significance in postoperative patients. Anesthesiology 95: 1356-1361.

38. Schag CC, Heinrich RL, Ganz PA (1984) Karnofsky performance status revisited: reliability, validity, and guidelines. J Clin Oncol 2: 187-193.
39. Binkley JM, Stratford PW, Lott SA, Riddle DL (1999) The Lower Extremity Functional Scale (LEFS): scale development, measurement properties, and clinical application. North American Orthopaedic Rehabilitation Research Network. Phys Ther 79: 371-383.

40. Fairbank JC, Pynsent PB (2000) The oswestry disability index. Spine 25 2940-2952

41. Ferrera LA (2006) Focus on body mass index and health research. Nova Science Publishers Inc. New York, USA. pp. 1-27.

42. Kellgren JH, Lawrence JS (1957) Radiological assessment of osteo-arthrosis Ann Rheum Dis 16: 494-502.

43. Gibson MJ, Buckley J, Mawhinney R, Mulholland RC, Worthington BS (1986) Magnetic resonance imaging and discography in the diagnosis of disc degeneration. A comparative study of 50 discs. J Bone Joint Surg $\mathrm{Br} 68$ : 369-373.

44. Carrera GF, Haughton VM, Syvertsen A, Williams AL (1980) Computed tomography of the lumbar facet joints. Radiology 134: 145-148.

45. Lindblom K (1951) Discography of dissecting transosseous ruptures of intervertebral discs in the lumbar region. Acta Radiol 36: 12-16.

46. Adams MA, Dolan P, Hutton WC (1986) The stages of disc degeneration as revealed by discograms. J Bone Joint Surg $\mathrm{Br} 68$ : 36-41.

47. Janssen ME, Bertrand SL, Joe C, Levine MI (1994) Lumbar herniated disk disease: comparison of MRI, myelography, and post-myelographic CT scan with surgical findings. Orthopedics 17: 121-127.

48. Baikov ES, Baikalov AA (2017) Biomechanical and biochemical parameters of spinal motion segments and recurrent lumbar disc herniation. Hirurgia Pozvonochnika 14: 61-68.

49. Steultjens MP, Dekker J, van Baar ME, Oostendorp RA, Bijlsma JW (2000) Range of joint motion and disability in patients with osteoarthritis of the knee or hip. Rheumatology (Oxford) 39: 955-961.

50. Kaufman KR, Hughes C, Morrey BF, Morrey M, An KN (2001) Gait characteristics of patients with knee osteoarthritis. J Biomech 34: 907-915.

51. Holla JF, Steultjens MP, van der Leeden M, Roorda LD, Bierma-Zeinstra SM, et al. (2011) Determinants of range of joint motion in patients with early symptomatic osteoarthritis of the hip and/or knee: an exploratory study in the CHECK cohort. Osteoarthritis Cartilage 19: 411-419.

52. Altman RD (2016) Bone, joint and muscle disorders/joint disorders. Merck Sharp and Dohme Corp., a subsidiary of Merck \& Co., Inc., Kenilworth, NJ, USA.

53. Risbud MV, Shapiro IM (2014) Role of cytokines in intervertebral disc degeneration: Pain and disc-content. Nat Rev Rheumatol 10: 44-56.

54. Seguin CA, Pilliar RM, Roughley PJ, Kandel RA (2005) Tumor necrosis factor-alpha modulates matrix production and catabolism in nucleus pulposus tissue. Spine 30: 1940-1948.

55. Xiaogang M, Quanshan H, Liping Z, Kaken H (2017) The expression of cytokine and its significance for the intervertebral disks of Kazakhs. J Clin Lab Anal 31.

56. Felson DT, Anderson JJ, Naimark A, Walker AM, Meenan RF (1988) Obesity and knee osteoarthritis: The Framingham study. Ann Intern Med 109: 18-24.

\section{Acknowledgment}

The author acknowledges the assistance of Ayondeep Ganguly and Anondeeep Ganguly for coordinating patients and arranging all data from the biochemical analysis. The author also thanks Dr. Swapan Roy, Chief Biochemist at the Galaxy Medical Centre in Kolkata, India, for analyzing the biochemical parameters in the present study. 